\title{
A Trial-Based Economic Evaluation Comparing Spinal Cord Stimulation With Best Medical Treatment in Painful Diabetic Peripheral Neuropathy
}

Citation for published version (APA):

Slangen, R., Faber, C. G., Schaper, N. C., Joosten, E. A., van Dongen, R. T., Kessels, A. G., van Kleef, M., \& Dirksen, C. D. (2017). A Trial-Based Economic Evaluation Comparing Spinal Cord Stimulation With Best Medical Treatment in Painful Diabetic Peripheral Neuropathy. The Journal of Pain, 18(4), 405-414. https://doi.org/10.1016/j.jpain.2016.11.014

Document status and date:

Published: 01/04/2017

DOI:

10.1016/j.jpain.2016.11.014

Document Version:

Publisher's PDF, also known as Version of record

Document license:

Taverne

Please check the document version of this publication:

- A submitted manuscript is the version of the article upon submission and before peer-review. There can be important differences between the submitted version and the official published version of record.

People interested in the research are advised to contact the author for the final version of the publication, or visit the DOI to the publisher's website.

- The final author version and the galley proof are versions of the publication after peer review.

- The final published version features the final layout of the paper including the volume, issue and page numbers.

Link to publication

\footnotetext{
General rights rights.

- You may freely distribute the URL identifying the publication in the public portal. please follow below link for the End User Agreement:

www.umlib.nl/taverne-license

Take down policy

If you believe that this document breaches copyright please contact us at:

repository@maastrichtuniversity.nl

providing details and we will investigate your claim.
}

Copyright and moral rights for the publications made accessible in the public portal are retained by the authors and/or other copyright owners and it is a condition of accessing publications that users recognise and abide by the legal requirements associated with these

- Users may download and print one copy of any publication from the public portal for the purpose of private study or research.

- You may not further distribute the material or use it for any profit-making activity or commercial gain

If the publication is distributed under the terms of Article $25 \mathrm{fa}$ of the Dutch Copyright Act, indicated by the "Taverne" license above, 


\section{Accepted Manuscript}

A trial based economic evaluation comparing spinal cord stimulation with best medical treatment in painful diabetic peripheral neuropathy

Rachel Slangen, MSc., Catharina G. Faber, Ph.D., Nicolaas C. Schaper, Ph.D., Elbert A. Joosten, Ph.D., Robert T. van Dongen, Ph.D., Alfons G. Kessels, MD, MSc.,

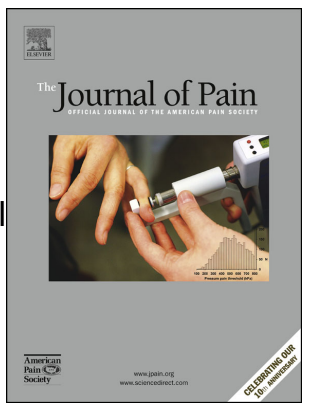
Maarten van Kleef, Ph.D., Carmen D. Dirksen, Ph.D.

PII:

$$
\text { S1526-5900(16)30352-2 }
$$

DOI:

$$
\text { 10.1016/j.jpain.2016.11.014 }
$$

Reference: $\quad$ YJPAI 3339

To appear in: Journal of Pain

Received Date: 16 March 2016

Revised Date: 22 November 2016

Accepted Date: 26 November 2016

Please cite this article as: Slangen R, Faber CG, Schaper NC, Joosten EA, van Dongen RT, Kessels $A G$, van Kleef $M$, Dirksen $C D, A$ trial based economic evaluation comparing spinal cord stimulation with best medical treatment in painful diabetic peripheral neuropathy, Journal of Pain (2017), doi: 10.1016/ j.jpain.2016.11.014.

This is a PDF file of an unedited manuscript that has been accepted for publication. As a service to our customers we are providing this early version of the manuscript. The manuscript will undergo copyediting, typesetting, and review of the resulting proof before it is published in its final form. Please note that during the production process errors may be discovered which could affect the content, and all legal disclaimers that apply to the journal pertain. 
A trial based economic evaluation comparing spinal cord stimulation with best medical treatment in painful diabetic peripheral neuropathy

\section{Short running title: cost-effectiveness of SCS in PDPN}

Rachel Slangen MSc. ${ }^{1}$; Catharina G. Faber Ph.D. ${ }^{2}$; Nicolaas C. Schaper, Ph.D. ${ }^{3}$; Elbert A. Joosten Ph.D. ${ }^{1}$; Robert T. van Dongen Ph.D. ${ }^{4}$; Alfons G. Kessels MD, MSc. ${ }^{5}$; Maarten van Kleef Ph.D. ${ }^{1}$ Carmen D. Dirksen Ph.D. ${ }^{56}$

1 Department of Anesthesiology and Pain Medicine, Maastricht University Medical Centre+, Maastricht, the Netherlands rachel.slangen@gmail.com; bert.joosten@maastrichtuniversity.nl; maarten.van.kleef@mumc.nl

${ }^{2}$ Department of Neurology, Maastricht University Medical Centre+, Maastricht, the Netherlands c.faber@mumc.nl

3 Department of Internal Medicine, Maastricht University Medical Centre, Maastricht, the Netherlands n.schaper@mumc.nl

${ }^{4}$ Department of Anesthesiology, Pain, and Palliative Care, Radboud University Medical Centre, Nijmegen, the Netherlands robert.vandongen@radboudumc.nl

${ }^{5}$ Department of Clinical Epidemiology and Medical Technology; Maastricht University Medical Centre+, Maastricht, the Netherlands c.dirksen@mumc.nl; fons.kessels@maastrichtuniversity.nl

${ }^{6}$ CAPHRI School of Public Health and Primary Care, Maastricht University, Maastricht, the Netherlands c.dirksen@mumc.nl 
Corresponding author:

R. Slangen

Maastricht University Medical Centre+

Department of Anesthesiology and Pain Medicine

PO Box 5800

6202 AZ Maastricht

the Netherlands

E-Mail: rachel.slangen@gmail.com

Disclosures The study was supported by Medtronic for providing a grant for the employment of one researcher for 3 years. Medtronic was not involved in the analysis and interpretation of the data and in writing the manuscript. No other potential conflicts of interest relevant to this article were reported. All authors declare that they have no conflicts of interests. 


\section{Abstract}

\section{ACCEPTED MANUSCRIPT}

The objective was to perform an economic evaluation comparing spinal cord stimulation in combination with best medical treatment (SCS) with best medical treatment (BMT) in painful diabetic peripheral neuropathy (PDPN) patients. Alongside a prospective two-center randomized controlled trial, involving 36 PDPN patients with severe lower limb pain, not responding to conventional therapy, an economic evaluation was performed. Incremental cost-effectiveness ratios (ICERs) were based on 1) societal costs and quality-adjusted life years (QALYs) and 2) direct healthcare costs and the number of successfully treated patients, respectively, both with a time horizon of 12 months. Bootstrap- and secondary analyses were performed to address uncertainty. Total societal cost amounted to $€ 26.539,18$ versus $€ 5.313,45$ per patient in the SCS and BMT group, respectively. QALYs were 0.58 versus 0.36 and the number of successfully treated patients was $55 \%$ versus $7 \%$ for the SCS and BMT group, respectively. This resulted in ICERs of $€ 94.159,56$ per QALY and $€ 34.518,85$ per successfully treated patient, respectively. Bootstrap analyses showed that the probability of SCS being cost-effective ranges from $0-46 \%$ with willingness to pay threshold values ranging between $€ 20.000-€ 80.000$ for a QALY. Secondary analyses showed that cost-effectiveness of SCS became more favorable after correcting for baseline cost imbalance between the two groups, extending the depreciation period of SCS material to 4 years, and extrapolation of the data up to 4 years. Although SCS was considerably more effective compared to BMT, the substantial initial investment that is required, resulted in SCS not being cost-effective at the short term. Cost-effectiveness results were sensitive to baseline cost imbalances between the groups and the depreciation period of the SCS material.

Trial Registry number: Clinicaltrials.gov ref. NCT01162993 
Perspective (50 words/50) Painful diabetic peripheral neuropathy is a common complication of diabetes mellitus and the humanistic and economic burden is high. This article presents the costeffectiveness of spinal cord stimulation in patients suffering from painful diabetic peripheral neuropathy from a societal and health care perspective with a time horizon of 12 months.

Keywords: Economic evaluation; Cost-Utility analysis; Cost-effectiveness Analysis; Diabetic Neuropathy; Painful Diabetic Neuropathy; Quality of Life 


\section{Introduction}

Diabetes Mellitus (DM) causes an enormous economic burden in many countries. An estimated 472 million $^{37}$ people suffer from diabetes worldwide, of which up to $50 \%$ develops diabetic peripheral neuropathy (DPN). The reported prevalence of painful diabetic peripheral neuropathy (PDPN) in a diabetic population ranges from $5.8-34 \% .^{2}$ This common, disabling disease accompanied with pain has a substantial impact on quality of life (QoL), $4,17,39$ and a profound effect on the health-care system. ${ }^{5,9,20}$ The societal impact is substantial, including the annual direct medical costs ${ }^{12}$ as well the indirect costs. The medical costs of PDPN may account for up to $27 \%$ of the direct costs of diabetes. ${ }^{16}$

The treatment of PDPN with pain medication is often unsuccessful and complicated by sideeffects. Given the limited effectiveness of pharmacological treatment, alternative treatment strategies have been sought to alleviate pain and improve QoL, including spinal cord stimulation (SCS). Up till now, several small retro- and prospective pilot studies were performed with promising results on pain and QoL. ${ }^{6,8,25,31,38}$ Recently, two randomized controlled trials $(\mathrm{RCT})^{7,32}$ were performed to evaluate the effects of SCS in PDPN patients, one of which by our institute. To date, no economic evaluation of SCS compared to best medical treatment (BMT) has been performed in PDPN patients.

The present study describes an trial based economic evaluation which was performed alongside the multicenter RCT, comparing the societal- and healthcare costs and outcomes of treatment with SCS with BMT as compared to BMT in patients suffering from PDPN. 


\section{Methods}

\section{ACCEPTED MANUSCRIPT}

\section{Study design and patients}

Details of the trial design, study characteristics and outcomes measurements have been published previously. ${ }^{32}$ In summary, 36 patients with PDPN in the lower limbs were included, and the study was performed in two Dutch Academic Hospitals from February 1, 2010, to February 28, 2013. Patients were screened for eligibility according to their clinical history and physical examination, which consisted of the Michigan Diabetic Neuropathy Score (MDNS). ${ }^{14}$ Main inclusion criteria were: moderate-to-severe PDPN with the pain being present for more than 12 months; pain intensity should be 5 or higher measured on a numeric rating scale (NRS); and previous treatment had been unsuccessful (insufficient pain relief and/or unacceptable side-effects). Following randomization, 22 patients were assigned to the spinal cord stimulation and best medical treatment (SCS) group and 14 patients to the best medical treatment (BMT) group. For the randomization a minimization program was used with the factors age, sex, type of DM, and severity of the PDPN according to the MDNS. A randomization ratio of 3:2 in favor of the SCS group was used. Of the 22 allocated patients to the SCS group, 17 patients (77\%) had a positive trial stimulation and received a definite SCS system. The study was approved by the institutional Medical Ethics Committee of the Maastricht University Medical Centre (ref. 09-2-120) and review board of the Radboud University Medical Centre Nijmegen, and registered with the CCMO (ref. NL30961.068.09) and Clinical Trials.gov (ref. NCT01162993). All patients gave written informed consent before participating in the study, according to the principles of the Declaration of Helsinki and could be identified only by number.

\section{Economic evaluation}

The economic evaluation was performed from a societal- and healthcare perspective, with a time horizon of 12 months in the base-case analysis. All patients were included in the economic evaluation based on the intention-to-treat principle, and data from quality of life questionnaires, 
case report forms, hospital records and cost questionnaires were analyzed. Data were obtained at baseline, 3, 6, 9 and 12 months for the SCS group and at baseline, 3 and 6 months for the BMT group (as after 6 months patients in the BMT group were offered SCS). The 6 month data of the BMT group were linearly extrapolated up to 12 months to compare effects and costs between both study groups.

\section{Outcome measures}

In the analysis from the societal perspective, the quality-adjusted life year (QALY) measure was chosen to represent health gain. The QALY is a measure of life expectancy weighted by healthrelated quality of life (HRQoL), the latter being presented as a utility score. In the present study, HRQoL was measured with the EuroQol five Dimensions (EQ-5D), ${ }^{18}$ a questionnaire widely used in economic evaluations. The EQ-5D consists of five dimensions (mobility, self-care, usual activities, pain/discomfort and anxiety/depression), each of which is rated at three levels (no problems, some problems, major problems), allowing 243 potential combinations of health states. These were converted into utility scores according to the Dutch tariff. ${ }^{10,26}$ QALYs were calculated according to the following formula for the SCS group: [[(utility score at baseline * 0.5$)+($ utility score at 3 months * 2.5)/3] ${ }^{*} 3 / 12+$ [(utility score at 3 months + utility score at 6 months)/2] ${ }^{*} 3 / 12+$ [(utility score at 6 months + utility score at 9 months $) / 2]{ }^{\star} 3 / 12+[($ utility score at 9 months + utility score at 12 months)/2] *3/12].

For the BMT group: [[(utility score at baseline + utility score at 3 months)/2] * 3/12 + [(utility score at 3 months + utility score at 6 months)/2] *3/12 + (utility score at 6 months *6/12] For the BMT group, utility score at 6 months was extrapolated up to 12 months according to the LOCF method.

In the analysis from the healthcare perspective, a successfully treated patient was used as outcome measure, defined as a patient experiencing $\geq 50 \%$ relief of pain intensity on a weighted numeric rating scale (NRS), for 4 days ${ }^{13}$ during daytime or nighttime, or a score of $\geq 6$ on a seven- 
point Likert scale (6=much improved; $7=$ very much improved) of the PGIC scale for pain and sleep at 12 months. The proportion of successfully treated patients in the BMT group at 6 months was assumed to represent the success rate at 12 months.

\section{Cost analysis}

The cost analysis was performed from a societal and healthcare perspective. All health care costs were assessed according to the Dutch guidelines for cost calculations in healthcare. ${ }^{19}$ Direct medical costs were grouped into two groups: costs related to the intervention, and costs incurred for other reasons attributable to PDPN and its treatment. Intervention costs (e.g. diagnostic procedures, treatment procedure, hospitalization, clinic visits, and telephone consultations), were retrieved from the hospital information system. Other healthcare costs (e.g. extramural: visits to general practitioner, diabetes nurse, general practitioner during weekend and evening, home care; intramural: emergency admissions, visits to diabetiologist, diabetic nurse, neurologist, pain specialist, inpatient hospital; paramedical: physiotherapy, ergo therapy, podotherapist pedicure and other health care professional visits; devices: orthopedic shoes and insoles and other devices; medication on prescription) and non-health care (paid domestic help, informal care giving, productivity loss, loss of daily activities and over-the-counter medication) were determined by means of cost questionnaires as filled out by the participants. ${ }^{11,15}$ The cost questionnaires were administered at baseline, 3, 6, 9 and 12 months (9 and 12 months for SCS only) with a recall period of 3 months. The cost questionnaire consisted of pre-defined resource use categories and patients were asked to complete all categories, regardless of whether or not applicable in that period. Patients were instructed to report PDPD related resource use only. Costs were calculated by multiplying resource use by the cost price per resource unit, and were expressed in 2012 euros $(€)$. Integral cost prices for resource use were primarily obtained from the Dutch manual for health care cost analysis. ${ }^{19}$ The reference unit prices of health care services for 2009 were adjusted to prices of 2012 by using the Dutch Consumer Price Index (CPI). ${ }^{29}$ If a guideline price was not 
readily available, an assumption was made based on an existing guideline price, or cost prices for were obtained from the financial department of Maastricht University Medical Centre, which included $78 \%$ of the patients. Intervention costs consisted of diagnostic test, the operation time per patient, general operating room costs, material costs of SCS, radiology assistance and admission of the patient, visits to the pain specialist, and pain nurse. In the base case analysis, material costs of SCS $(€ 9.557,07)$ were fully allocated to the first year. Cost prices per unit of resource are presented in Table 1. Cost prices for medication were derived from the Medication and Aid Information Project database (medicijnkosten.nl), and were calculated for pain medication, and included claw-back and taxes. Productivity losses due to sick leave were calculated using the friction method, in which production losses are confined to the period needed to replace a sick worker. $^{23,24}$

\section{Statistical analysis}

All analyses were based on the 'intention-to-treat' principle. Incomplete- and missing data were imputed, using SPSS 22 Multiple Imputation (predictive mean matching) (SPSS in, Chicago, Illinois, USA), under the assumption that data was missing at random. Covariates included in the imputation model were all the 23 questions of the cost questionnaire obtained at all-time points, and for the SCS and BMT group separately. Additionally age, sex and successful trial stimulation were included in the model. In total, 5 imputed data sets were obtained. Data analyses were performed with these sets and the results were presented as pooled estimates. Missing data at 12 months in the BMT group were imputed by linear extrapolation. ${ }^{33}$ Cost were not normally distributed and, therefore, differences between the SCS- and BMT group were compared using non-parametric bootstrapping with 95\% confidence intervals $(\mathrm{CI})$ around mean costs and effects of the two treatment groups, using Microsoft Excel for Windows (Microsoft Corp, Redmond, Washington, USA). Differences in baseline characteristics between the SCS group and the BMT group in resource use, costs and QALYs were reported descriptively. Utility scores were corrected 
for an observed imbalance between the SCS group and the BMT group at baseline. An imbalance can have a major impact, as the baseline utility score is included in the QALY calculation. Utility values were corrected with the mean absolute difference method and used for calculation of QALYs in the base case analysis. ${ }^{27}$

To evaluate cost-effectiveness between the SCS- and BMT group, incremental costeffectiveness ratios (ICERs) were calculated by dividing the difference in costs by the difference in effectiveness between the two treatment groups. Additionally, non-parametric bootstrap analysis with 1000 replications on the costs and effects were performed. Results were plotted in an incremental cost-effectiveness plane in which the horizontal axis presents the incremental effect, and the vertical axis represents the incremental cost between SCS and BMT. The probability that SCS is cost-effective is graphically displayed in a cost-effectiveness acceptability curve (CEAC). Maximum willingness to pay thresholds of $€ 20.000$ and $€ 80.000$ per QALY gain were used for judging the cost-effectiveness of SCS. ${ }^{42}$

\section{Secondary analyses}

To assess the robustness of the results of the base-case analysis, sensitivity analyses were performed. First, a correction for a baseline difference between both groups in the cost item loss of daily activities was performed. Calculation with these uncorrected data would lead to an overestimation of the ICER. Therefore, we corrected the difference in baseline loss of daily activities according to the mean absolute difference method. ${ }^{40}$ The baseline difference in costs due to loss of daily activities was added to the value at all measurements in the BMT group. Second, the cost of implanted SCS material was dispersed over a period of 4 years instead of 1 because of the longevity of the SCS material (battery life of the pulse generator, life of the lead and extension). ${ }^{30}$ Third, a sensitivity analysis was performed with the baseline cost difference correction and a depreciation period of SCS material of 4 years. Furthermore, a secondary analysis was performed with a 6 months' time horizon, using only empirical data for both SCS- and 
BMT group.

In addition, data of the base-case analysis and sensitivity analyses were extrapolated up to a 4 years' time horizon. SCS intervention costs were extrapolated based on the costs incurred in the period of 6 till 12 months, multiplied by 6 . Other health care costs and non-health care costs were extrapolated based on costs incurred in 12 months. All costs were linearly extrapolated and discounted with $4 \%$ for each year ${ }^{19}$ for both treatment groups. For the SCS group, empirically obtained utility scores at 24 months were available, ${ }^{41}$ and extrapolated up to four years assuming that the utility score remained stable at three and four years. Utility scores were discounted with $1.5 \%{ }^{19}$ Next, QALYs were calculated based on the utility scores. For the BMT group, utility score of 6 months was extrapolated up to four years. The ICERs of the base-case and sensitivity analyses were plotted in a figure with a range of willingness to pay threshold between 20.000 euros/QALY gain and 80.000 euros/QALY gain. ${ }^{1,42}$ Extrapolation of data from the health care perspective, was based on empirically obtained proportions of successfully treated patients in the SCS group at 24 months $^{41}$ and for BMT at 6 months, and extrapolated up to four years assuming that these proportions remained stable. Proportions of successfully treated patients were discounted with $1.5 \% .^{19}$ 


\section{Results}

\section{Patients}

Data of 36 patients were analyzed in the cost-effectiveness analysis. In Table 2, patient characteristics are displayed. Mean age was $57.1 \pm 12.4$ and $56.5 \pm 8.0$ years in the SCS group, and BMT group, respectively. There were no statistically significant differences between the groups at baseline.

In case of three patients in the SCS group, data were only available at baseline: 1) in one patient, the implantation of the stimulation lead, was complicated by a dural puncture, leading to the death of the patient $\left.{ }^{32} ; 2\right)$ one patient was not willing to fill out questionnaires after negative trial stimulation; 3) after six weeks, another patient withdrew from the study due to infection and removal of the SCS system. In addition, one patient was lost to follow-up after 6 months and another patient after 9 months in the SCS group. In the BMT group, data was missing from 1 patient at 3 months (Supplementary Fig. 1). All 6 patients with missing data were retained in the analysis.

Complications were noticed in 5 patients during follow-up in the SCS group, including lead revision, lead replacement, replacement of a battery, infection of the SCS system, and a subdural hematoma.

\section{Outcome measures}

Baseline utility was remarkably although not statistically significant $(P=0.46)$ higher $(0.08)$ in the BMT group than in the SCS group (Table 2). For the deceased patient, the utility score of the postmeasurements was set to 0 . The utility scores for patients randomized to the SCS group were 0.25 at baseline, 0.51 at 3 months, 0.46 at 6 months, 0.49 at 9 months and 0.48 at 12 months. For patients in the BMT group, utility scores were 0.33 at baseline, 0.43 at 3 months and 0.33 at 6 months (Supplementary Fig. 2). The calculated QALYs were 0.50 and 0.36 in the SCS- and BMT group, respectively. After adjustment for the baseline imbalance in utility scores with 0.08 , the 
corrected QALY's, which were used for the base case analysis, were 0.58 and 0.36 in the SCSand BMT group, respectively.

In the SCS group 12 out of 22 patients (55\%) were successfully treated, compared to 1 out of 14 patients $(7 \%)$ in the BMT group $(\mathrm{P}<0.009)$.

\section{Cost analysis}

Table 1 shows the cost per resource unit and the mean costs per patient on intervention cost, other health care costs, non-health care costs, and total societal costs. For the deceased patient the costs were set at zero from 10 days post-surgery (time of death).

Table 3 shows the subtotal health care costs, subtotal non-health care costs, and the total societal costs, including bootstrap analysis. In the base-case analysis, total societal costs amounted to $€ 26.539,20$ and $€ 5.313,45$ per patient in the SCS and BMT group, respectively, and were significantly higher for the SCS group. Total societal costs in the SCS group were dominated by the intervention costs, and non-health care costs, including informal care, productivity loss and loss of daily activities.

The intervention costs amounted to $€ 16.579,92$, and $€ 341,97$ in the SCS group and BMT group, respectively. The high costs for SCS were mainly due to the implanted material, which formed $58 \%$ of the total costs related to the treatment. Intervention costs also included complications related to the SCS treatment (Table 1), amounting to $€ 2.388,00$. Other health care costs were not significantly different between the SCS- and BMT group, with a difference of $€ 331,10$ in favor of the BMT group. The subtotal health care costs amounted to $€ 18.742,18$ and $€ 2.173,13$ in the SCS- and BMT group, respectively.

Costs outside the health care sector (non-health care) were $€ 7.797,00$ and $€ 3.140,32$ in the SCS and BMT group, respectively which was statistically different, including difference in costs by informal care, productivity loss and loss of daily activities. Remarkably, the informal care costs were more than quadrupled in the SCS group as compared to the BMT group. In both groups, 
informal care costs decreased in the first half year after treatment as compared to baseline. Contrary, the SCS group generated more costs in the second half year as compared to baseline. Costs due to loss of daily activities showed a difference in favor of the BMT group. In the SCS group, costs due to loss of daily activities decreased in the first half year following treatment as compared to baseline, but increased in the second half year as compared to the first half year.

Productivity costs were significantly higher in the SCS group and could be fully attributed to the first half year following treatment.

\section{Cost effectiveness}

Table 4 shows the results regarding the cost-effectiveness of the base-case analysis. SCS yielded the most QALYs, but also incurred more costs, resulting in an ICER of €94.159,56 per QALY for SCS versus BMT. The ICER from the health care perspective was $€ 34.518,85$ per successfully treated patient. Bootstrap analyses revealed that the majority of cost-effectiveness ratios, both for the societal and healthcare perspective, is situated in the North-east quadrant, meaning that SCS is more costly and more effective than BMT. From a societal perspective, the CEAC (Fig. 1) illustrates that with a range of willingness to pay threshold of $€ 20.000-€ 80.000 / Q A L Y,{ }^{19,28}$ the probability that SCS is cost-effective ranged between 0 and $46 \%$.

\section{Secondary analyses}

At baseline, non-health care costs were significantly higher in the SCS group, which was mainly due to costs due to loss in daily activities (€1.105,38 higher in SCS group).

In Table 4, the results of the secondary analyses are shown. All secondary analyses revealed that the ICERs decreased as compared to the base-case analysis. When correcting for baseline differences in costs and extending the depreciation period of the SCS material to four years, SCS would be cost-effective if society would be willing to pay $€ 51.393,20$ per QALY. The probability that SCS is cost-effective is $85 \%$ with a willingness to pay threshold of $€ 80.000$ (Fig. 1). The secondary analysis with a time horizon of 6 months revealed an ICER of $€ 117.814,69$ per 
QALY.

Figure 2 shows the data of the base-case- and secondary analyses extrapolated up to four years, with a range of willingness to pay thresholds between €20.000/QALY gain and $€ 80.000 /$ QALY gain. The QALY gained at up till 0.56 at 24 months, whereas the proportions of successfully treated patients at 24 months was $50 \%$. SCS becomes more cost-effective assuming a threshold of $€ 80.000$ per QALY within 1year with a correction of extending the depreciation period of the SCS material to 4 years, with a ICER of $€ 62.774,71$ per QALY. Extrapolation of the health care perspective revealed an increasing ICER of $€ 34.518,71$ up to $€ 52.252,01$ per successfully treated patient at 4 years, respectively. 


\section{Discussion}

ACCEPTED MANUSCRIPT

This economic evaluation compared the costs and effects of SCS versus BMT for PDPN patients with a time horizon of 12 months. SCS yielded more QALY's than BMT, 0.58 and 0.36 in the SCS and BMT group, respectively. Total societal costs were $€ 26.539,20$ and $€ 5.313,45$ per patient in the SCS and BMT group, respectively, and were significantly higher for the SCS group. The high costs could be attributed to the amount of costs related to the SCS intervention (e.g. SCS material, surgery and hospital admission etc.). Based on the base-case results, the ICER of SCS versus BMT was $€ 94.159,56$ per QALY. The probability of SCS being cost-effective was $46 \%$ when applying a willingness to pay threshold of $€ 80.000$, indicating SCS is not cost-effective at the short term. From the health care perspective, the ICER was $€ 34.518,85$ per successfully treated patient at 12 months. Secondary analyses showed that these results were not robust. When correcting for baseline differences in costs and utility and extending the depreciation period of the SCS material to 4 years, the ICER decreased to $€ 51.393,20$ per QALY. Extrapolation of the data revealed that SCS is likely to become cost-effective at the longer term.

Randomization was performed using a computerized randomization program in which patients were stratified by age, sex, type of DM and severity of the PDPN according to the MDNS. Nevertheless, we found a non-significant, but pronounced difference in utility values between both groups at baseline, which may seriously impact upon the ICER. In addition, an unexpected nonsignificant baseline cost difference in the item loss of daily activities was found between the SCS and BMT group. Although both differences were not significant, we nevertheless corrected for the imbalance in the utility score and cost item according to the mean absolute difference method. ${ }^{27,40}$ This is a simple and robust method, however it is the strictest correction which assumes that the baseline difference pertains over time.

From the societal perspective, non-health care costs due to informal care, productivity loss, and loss of daily activities, were reported higher in the SCS group during the 12 months follow-up period. The increase in productivity costs compared to baseline in the SCS group in the first half 
year following treatment could be explained by the fact that patients had to call in sick because of recovering from the SCS implantation. There is no obvious explanation for first the decrease in costs due to informal care and loss of daily activities in the first half year following treatment and later again the increase in costs in the second half year in the SCS group. However, it may indicate that the return to work in the second half year following treatment is accompanied by increased use of informal care and reduced hours of domestic activities. The higher costs due to loss of daily activities in the BMT group compared to baseline could possibly be explained by a variety of factors inherent to PDPN.

To our knowledge, there are no earlier publications on cost-effectiveness of SCS treatment and follow-up in PDPN patients. However, similar studies have been conducted in patients with other conditions, including failed back surgery syndrome (FBSS), ${ }^{3,35,43}$ chronic reflex sympathetic dystrophy (CRPS), ${ }^{21}$ and angina pectoris (AP). ${ }^{35}$ Health care costs related to the SCS treatment are almost identical to those reported in other studies. ${ }^{35,43}$ For example, the most recently published RCT in FBSS patients ${ }^{43}$ showed similar SCS intervention costs, $€ 16.872,00$ as compared to $€ 16.579,92$ in our study. From a societal perspective, total costs were $€ 20.902 /$ patient-year as compared to $€ 26.539,18 /$ patient-year, in our study. This cost difference can be explained by the fact that we included more items in our calculations of non-health care cost (e.g. paid domestic help, productivity loss, and loss of daily activities). In addition, PDPN patients probably generate more costs in health care than FBSS patients, because they suffer from more complications due to their painful neuropathy. Studies regarding FBSS and CRPS, reported that the initial costs of SCS were offset by a reduction in health care expenditure at a longer time horizon varying from 15 months till lifetime., $31,35,36$ In our study we did not observe a decrease in health care- and non-health care costs following SCS implantation. On the contrary, non-health care costs increased in the second half year following treatment as compared to baseline. At current, evidence of cost-effectiveness is poor as only a few RCT's have been performed. Additionally, comparison with other studies is difficult because of different outcome 
measures, different time-horizons, as well different perspectives (only health care perspective) and a lack of and/or using different non-health care costs.

The strength of our study was that our economic evaluation was performed according to the Dutch guidelines for trial based economic evaluations, ${ }^{19,28}$ within a multicenter RCT. Additionally, we presented the results from both a societal and healthcare perspective. Finally, we tested the robustness of our results through several secondary analyses and presented a model for extrapolation up to four years.

Our study had some limitations. First, in case of three patients only the baseline measurement was present. These patients were included in the ITT analysis with imputed data taking into account whether they had a positive-or negative trial stimulation, age and sex. Second, a part of the cost data was collected retrospectively, potentially causing some recall bias, e.g. some amounts were forgotten or not precisely remembered by the patients. However, the retrospective time period was three months, and was considered as a reasonable period to obtain reliable data. ${ }^{15}$ Third, the data of the BMT group was linearly extrapolated up to 12 months, assuming no change between 6 and 12 months follow up in this group. Although this can be considered a limitation, on the other hand it assumes that the BMT group does not deteriorate over time. Fourth, because of the time horizon of 12 months, this study only provides an indication of the short term cost-effectiveness of SCS versus BMT. Because painful diabetic peripheral neuropathy is a chronic pain condition and will probably even get worse in time, a time horizon of the patient lifetime would be more appropriate, including more real life time data on costs and QoL. We conducted a simple linear extrapolation of the data, assuming that cost and outcome data remain stable over time, to estimate cost-effectiveness with a longer time horizon. The longevity of the implanted battery (approximately four years) ${ }^{30}$ was chosen as time horizon for the extrapolation. Although our extrapolation indicated that SCS is likely to become cost-effective at the long term, this result is highly uncertain. A thorough decision analytic model would provide better insight in the long-term cost-effectiveness of SCS in this patient group. However, to facilitate 
model input, more empirical follow-up data, including life expectancy, longevity of the SCS material, ${ }^{3,21,35,36}$ complication- and implantation rate and costs are needed. Model-based costeffectiveness analyses in FBSS and CRPS have revealed that SCS will be more cost-effective on the long term. ${ }^{22,34}$

We conclude that SCS was not cost-effective compared to BMT at 12 months follow-up, mainly due to the high initial investment costs of SCS. Secondary analyses showed that the ICER dropped considerably when correcting for baseline differences in costs, and extending the depreciation period of the SCS material to 4 years.

\section{Acknowledgements}

The authors thank the members of the multidisciplinary steering committee for designing and guiding the protocol. Special thanks to M.N. Janssen MD, R.T. van Dongen MD, PhD, and M.A. Steegers MD, PhD, who implanted most of the SCS systems and W. Lardenoye-Somers, E. JansMeers, I. Arnts and P. Verstegen for the guidance of the patients, and M. Geerts for recruiting patients. We are indebted to the colleagues who referred candidates for the study to our department and to the patients who participated in the study.

Author Contributions. R.S. contributed to the study design and analysis and interpretation of the data, and wrote the manuscript. CG.F. contributed to the study design, and contributed to writing the manuscript. NC.S. contributed to the study design, and reviewed the manuscript. EA.J. contributed to the study design, and reviewed the manuscript. RT.v.D. contributed to the study design and reviewed the manuscript. AG.K. contributed to the study design and analyses, and reviewed the manuscript. M.K contributed to the study design, and reviewed the manuscript. C.D. contributed to the study design, analysis and interpretation of the data and contributed to writing the manuscript. Prof. Dr. Carmen D. Dirksen is the guarantor of this work and, as such, had full 
access to all the data in the study and takes responsibility for the integrity of the data and the accuracy of the data analysis. 
1. Sensible and sustainable care [in Dutch].(Care CfPHaH, Ed.), The Netherlands, Den Haag, 2006.

2. Alleman CJ, Westerhout KY, Hensen M, Chambers C, Stoker M, Long S, van Nooten FE: Humanistic and economic burden of painful diabetic peripheral neuropathy in Europe: A review of the literature. Diabetes research and clinical practice 109:215-225, 2015

3. Bala MM, Riemsma RP, Nixon J, Kleijnen J: Systematic review of the (cost-)effectiveness of spinal cord stimulation for people with failed back surgery syndrome. The Clinical journal of pain $24: 741-756,2008$

4. Barrett AM, Lucero MA, Le T, Robinson RL, Dworkin $\mathrm{RH}$, Chappell AS: Epidemiology, public health burden, and treatment of diabetic peripheral neuropathic pain: a review. Pain medicine (Malden, Mass 8 Suppl 2:S50-62, 2007

5. daCosta DiBonaventura M, Cappelleri JC, Joshi AV: A longitudinal assessment of painful diabetic peripheral neuropathy on health status, productivity, and health care utilization and cost. Pain medicine (Malden, Mass 12:118-126, 2011

6. Daousi C, Benbow SJ, MacFarlane IA: Electrical spinal cord stimulation in the long-term treatment of chronic painful diabetic neuropathy. Diabet Med 22:393-398, 2005

7. de Vos CC, Meier K, Zaalberg PB, Nijhuis HJ, Duyvendak W, Vesper J, Enggaard TP, Lenders MW: Spinal cord stimulation in patients with painful diabetic neuropathy: a multicentre randomized clinical trial. Pain 155:2426-2431, 2014

8. de Vos CC, Rajan V, Steenbergen W, van der Aa HE, Buschman HP: Effect and safety of spinal cord stimulation for treatment of chronic pain caused by diabetic neuropathy. Journal of diabetes and its complications 23:40-45, 2009

9. DiBonaventura MD, Cappelleri JC, Joshi AV: Association between pain severity and health care resource use, health status, productivity and related costs in painful diabetic peripheral neuropathy patients. Pain medicine (Malden, Mass 12:799-807, 2011 
10. Dolan P: Modeling valuations for EuroQol health states. Medical care 35:1095-1108, 1997

11. Drummond M, Sculpher MJ, Torrance GW, O'Brien BJ, Stoddart GL: Methods for the Economic Evaluation of Health Care Programmes. 3rd edition, Oxford University Press, Oxford, 2005.

12. Dworkin RH, Panarites CJ, Armstrong EP, Malone DC, Pham SV: Healthcare utilization in people with postherpetic neuralgia and painful diabetic peripheral neuropathy. Journal of the American Geriatrics Society 59:827-836, 2011

13. Dworkin $\mathrm{RH}$, Turk DC, Wyrwich KW, Beaton D, Cleeland CS, Farrar JT, Haythornthwaite JA, Jensen MP, Kerns RD, Ader DN, Brandenburg N, Burke LB, Cella D, Chandler J, Cowan P, Dimitrova R, Dionne R, Hertz S, Jadad AR, Katz NP, Kehlet H, Kramer LD, Manning DC, McCormick C, McDermott MP, McQuay HJ, Patel S, Porter L, Quessy S, Rappaport BA, Rauschkolb C, Revicki DA, Rothman M, Schmader KE, Stacey BR, Stauffer JW, von Stein T, White RE, Witter J, Zavisic S: Interpreting the clinical importance of treatment outcomes in chronic pain clinical trials: IMMPACT recommendations. J Pain $9: 105-121,2008$

14. Feldman EL, Stevens MJ, Thomas PK, Brown MB, Canal N, Greene DA: A practical twostep quantitative clinical and electrophysiological assessment for the diagnosis and staging of diabetic neuropathy. Diabetes care 17:1281-1289, 1994

15. Goossens ME, Rutten-van Molken MP, Vlaeyen JW, van der Linden SM: The cost diary: a method to measure direct and indirect costs in cost-effectiveness research. Journal of clinical epidemiology 53:688-695, 2000

16. Gordois A, Scuffham P, Shearer A, Oglesby A, Tobian JA: The health care costs of diabetic peripheral neuropathy in the US. Diabetes care 26:1790-1795, 2003

17. Gore M, Brandenburg NA, Hoffman DL, Tai KS, Stacey B: Burden of illness in painful diabetic peripheral neuropathy: the patients' perspectives. J Pain 7:892-900, 2006 
18. Group TE: EuroQol--a new facility for the measurement of health-related quality of life. The EuroQol Group. Health policy (Amsterdam, Netherlands) 16:199-208, 1990

19. Hakkaart- van Roijen L, Tan SS, Bouwmans CAM: Handleiding voor kostenonderzoek. Methoden en standaard kostprijzen voor economische evaluaties in de gezondheidszorg., ZiNL, Diemen, 2010.

20. Happich M, John J, Stamenitis S, Clouth J, Polnau D: The quality of life and economic burden of neuropathy in diabetic patients in Germany in 2002--results from the Diabetic Microvascular Complications (DIMICO) study. Diabetes research and clinical practice $81: 223-230,2008$

21. Kemler MA, Furnee CA: Economic evaluation of spinal cord stimulation for chronic reflex sympathetic dystrophy. Neurology 59:1203-1209, 2002

22. Kemler MA, Raphael JH, Bentley A, Taylor RS: The cost-effectiveness of spinal cord stimulation for complex regional pain syndrome. Value Health 13:735-742, 2010

23. Koopmanschap MA: PRODISQ: a modular questionnaire on productivity and disease for economic evaluation studies. Expert review of pharmacoeconomics \& outcomes research $5: 23-28,2005$

24. Koopmanschap MA, Rutten FF, van Ineveld BM, van Roijen $L$ : The friction cost method for measuring indirect costs of disease. Journal of health economics 14:171-189, 1995

25. Kumar K, Toth C, Nath RK: Spinal cord stimulation for chronic pain in peripheral neuropathy. Surgical neurology 46:363-369, 1996

26. Lamers LM, McDonnell J, Stalmeier PF, Krabbe PF, Busschbach JJ: The Dutch tariff: results and arguments for an effective design for national EQ-5D valuation studies. Health economics 15:1121-1132, 2006

27. Manca A, Hawkins N, Sculpher MJ: Estimating mean QALYs in trial-based costeffectiveness analysis: the importance of controlling for baseline utility. Health economics $14: 487-496,2005$ 
28. Nederland Z: Richtlijn voor het uitvoeren van economische evaluaties in de gezondheidszorg ZiNL, Diemen, 2015.

29. Netherlands S: www.cbs.nl

30. Neuromodulation M: Medtronic Neuromodulation 2013 Product Performance Report: Spinal Cord Stimulations Systems, Medtronic, USA, 2014.

31. Pluijms WA, Slangen R, Joosten EA, Kessels AG, Merkies IS, Schaper NC, Faber CG, van Kleef M: Electrical spinal cord stimulation in painful diabetic polyneuropathy, a systematic review on treatment efficacy and safety. European journal of pain (London, England) 15:783-788, 2011

32. Slangen R, Schaper NC, Faber CG, Joosten EA, Dirksen CD, van Dongen RT, Kessels AG, van Kleef M: Spinal cord stimulation and pain relief in painful diabetic peripheral neuropathy: a prospective two-center randomized controlled trial. Diabetes care 37:30163024, 2014

33. Streiner DL: The case of the missing data: methods of dealing with dropouts and other research vagaries. Canadian journal of psychiatry. Revue canadienne de psychiatrie 47:6875,2002

34. Taylor RJ, Taylor RS: Spinal cord stimulation for failed back surgery syndrome: a decisionanalytic model and cost-effectiveness analysis. International journal of technology assessment in health care 21:351-358, 2005

35. Taylor RS, Taylor RJ, Van Buyten JP, Buchser E, North R, Bayliss S: The cost effectiveness of spinal cord stimulation in the treatment of pain: a systematic review of the literature. Journal of pain and symptom management 27:370-378, 2004

36. Taylor RS, Van Buyten JP, Buchser E: Spinal cord stimulation for complex regional pain syndrome: a systematic review of the clinical and cost-effectiveness literature and assessment of prognostic factors. European journal of pain (London, England) 10:91-101, 2006 
37. Tesfaye S, Selvarajah D: Advances in the epidemiology, pathogenesis and management of diabetic peripheral neuropathy. Diabetes/metabolism research and reviews 28 Suppl 1:814,2012

38. Tesfaye S, Watt J, Benbow SJ, Pang KA, Miles J, MacFarlane IA: Electrical spinal-cord stimulation for painful diabetic peripheral neuropathy. Lancet 348:1698-1701, 1996

39. Tolle T, Xu X, Sadosky AB: Painful diabetic neuropathy: a cross-sectional survey of health state impairment and treatment patterns. Journal of diabetes and its complications 20:2633, 2006

40. van Asselt $A D$, van Mastrigt GA, Dirksen CD, Arntz A, Severens JL, Kessels AG: How to deal with cost differences at baseline. PharmacoEconomics 27:519-528, 2009

41. van Beek M, Slangen R, Schaper NC, Faber CG, Joosten EA, Dirksen CD, van Dongen RT, Kessels AG, van Kleef M: Sustained Treatment Effect of Spinal Cord Stimulation in Painful Diabetic Peripheral Neuropathy: 24-Month Follow-up of a Prospective Two-Center Randomized Controlled Trial. Diabetes care 38:e132-134, 2015

42. van Hout BA, Al MJ, Gordon GS, Rutten FF: Costs, effects and C/E-ratios alongside a clinical trial. Health economics 3:309-319, 1994

43. Zucco F, Ciampichini R, Lavano A, Costantini A, De Rose M, Poli P, Fortini G, Demartini L, De Simone E, Menardo V, Cisotto P, Meglio M, Scalone L, Mantovani LG: CostEffectiveness and Cost-Utility Analysis of Spinal Cord Stimulation in Patients With Failed Back Surgery Syndrome: Results From the PRECISE Study. Neuromodulation : journal of the International Neuromodulation Society 18:266-276; discussion 276, 2015 


\section{ACCEPTED MANUSCRIPT}

Table 1 Mean costs per unit and patient (in euros) with a time horizon of 12 months in PDPN patients.

SCS, spinal cord stimulation group; BMT, best medical treatment group; AH Academic Hospital; ${ }^{\text {a }}$ Expressed in 2012 Euros; ${ }^{b}$ Financial Department of Maastricht University Medical Centre $+;{ }^{c}$ ZiNL: Dutch governmental manual for health care cost analysis; ${ }^{d}$ Informed assumption ZiNL: Dutch governmental manual for health care cost analysis.

\section{Table 2 Baseline demographics and clinical characteristics of the study population.*}

*Plus-minus values are means \pm SD. DM: Diabetes Mellitus.

† The Michigan Diabetic Neuropathy Score (MDNS) consists of a standardized neurological examination, including vibration sense, light touch, pin prick, tendon reflexes and muscle strength and standard nerve conduction study of 2 motor nerves (peroneal and median) and 3 sensory nerves (sural, median and ulnar) performed on the non-dominant site. Classes are defined as $0=$ no neuropathy; $1=$ mild neuropathy; $2=$ moderate neuropathy and $3=$ severe neuropathy.

‡ The EuroQol-5 dimension questionnaire (EQ-5D) is a health status measure with respect to mobility, self-care, usual activities, pain or discomfort, and anxiety or depression (no problems, some problems, and extreme problems). A utility score of 1 represents "perfect health", 0 represents "death"; and less than 0 "worse than death".

$P$ values were calculated with the use of chi-square test for categorical variables and the independent-samples Student's t-test for continuous variables. No significant between-group differences were observed for any demographic and clinical characteristics. Values are percentages (numbers) unless stated otherwise. SCS: spinal cord stimulation group; BMT: best medical treatment group; DM: diabetes mellitus; MDNS: Michigan Diabetic Neuropathy Score

Table 3 Bootstrap analyses of the base-case analysis on subtotal and total health care costs for the SCS- and BMT group with a time horizon of 12 months.

Table 4 Results of the base-case-, secondary and sensitivity analyses for SCS and BMT, regarding costs and effects, and incremental cost-effectiveness ratio's (ICER's) with a time horizon of 12 months.

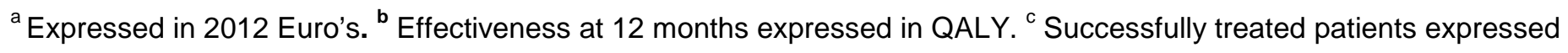
in percentage. ' ICER's: incremental cost-effectiveness ratio's. ${ }^{e}$ Showing the quadrant were the most points are located 
expressed in percentage; northwest (NW) quadrant: SCS is more costly and less effective than BMT (inferior); northeast (NE) quadrant: SCS is more costly and more effective than BMT meaning that the cost-effectiveness of SCS depends on the maximum amount of money society is willing to pay for one gain in effectiveness; southeast (SE) quadrant: SCS is less costly and more effective than BMT (dominant); and southwest (SW) quadrant: SCS is less costly and less effective than BMT, meaning that the cost-effectiveness of SCS depends on the minimum amount of money society is willing to accept for loss of effectiveness. ${ }^{\dagger}$ WTP: willingness to pay threshold of $€ 80.000$. 
FIGURE LEGENDS

\section{ACCEPTED MANUSCRIPT}

Figure 1 Cost-effectiveness acceptability curve base-case and secondary analyses per QALY expressed in 2012 Euros.

The curve shows the probability (vertical axis) if SCS (base-case and secondary analysis) is cost effective over a range of values for the maximum acceptable ceiling ratio (horizontal axis).

0) Base case analysis; 1) Correction of baseline difference in loss of daily activities; 2) depreciation period of implanted SCS material up to 4 years 3) Correction of baseline difference in loss of daily activities and depreciation period of SCS material up to 4 years.

Figure 2 Extrapolation of the base-case analysis and secondary analyses up to 4 years from a societal perspective

0) Base case analysis; 1) Correction of baseline difference in loss of daily activities; 2) depreciation period of implanted SCS material up to 4 years 3) Correction of baseline difference in loss of daily activities and depreciation period of SCS material up to 4 years.

The black horizontal lines showing the willingness to pay thresholds of $€ 20.000$ euros/QALY gain and $€ 80.000$ euros/QALY gain. 
TABLES

Table 1 Mean costs per unit and patient (in euros) with a time horizon of 12 months in PDPN patients.

\begin{tabular}{|c|c|c|c|c|c|}
\hline & & \multicolumn{2}{|c|}{ Mean costs $0-6$ months } & \multicolumn{2}{|c|}{ Mean costs $0-12$ months } \\
\hline & $\begin{array}{c}\text { Cost per resource } \\
\text { unit }^{\mathrm{a}}\end{array}$ & SCS & BMT & SCS & BMT \\
\hline Intervention costs & & $15.783,25$ & 308,11 & $16.579,92$ & 341,97 \\
\hline Pre-intervention costs & & 260,73 & 268,76 & 260,73 & 268,76 \\
\hline $\begin{array}{l}\text { First consultation pain } \\
\text { specialist }\end{array}$ & $92,08 /$ visit $^{b}$ & 92,08 & 2,08 & 92,08 & 92,08 \\
\hline EMG & $176,68 / \mathrm{EMG}^{\mathrm{b}}$ & 168,65 & 176,68 & 168,65 & 176,68 \\
\hline Per-intervention costs & & $13.682,88$ & 10,99 & $13.691,05$ & 16,49 \\
\hline Time of surgical operation & $1,15 / \mathrm{min}^{\mathrm{b}}$ & 141,29 & - & 141,29 & - \\
\hline $\begin{array}{l}\text { Total surgical operation } \\
\text { time }\end{array}$ & $11,49 / \mathrm{min}^{\mathrm{b}}$ & 1996,13 & - & 1996,13 & - \\
\hline Infusion medication & $120,09 /$ infusion $^{b}$ & 229,26 & - & 229,26 & - \\
\hline
\end{tabular}




\begin{tabular}{|c|c|c|c|c|c|}
\hline $\begin{array}{l}\text { Radiology (assistance and } \\
\text { x-ray) }\end{array}$ & $600,08 /$ operation $^{b}$ & 551,50 & - & 551,50 & - \\
\hline SCS electrode & $2737,48 /$ electrode $^{b}$ & $2.737,48$ & - & $2.737,48$ & - \\
\hline SCS extension & $983,36 /$ extension $^{b}$ & 759,87 & - & 759,87 & - \\
\hline SCS battery & $7841,99 /$ battery $^{b}$ & $6.059,72$ & - & $6.059,72$ & - \\
\hline Admission & $311,13 /$ day $\mathrm{AH}^{\mathrm{D}}$ & $1.179,70$ & - & $1.179,70$ & - \\
\hline $\begin{array}{l}\text { Laboratory assays (glucose } \\
\text { curves, } \mathrm{HbA1c} \text { ) }\end{array}$ & $\begin{array}{l}\text { 2,36/essay (glucose } \\
\text { curves) }^{\text {b }} \\
\text { 9,99/essay (HbA1c) }\end{array}$ & 27,93 & 10,99 & 36,10 & 16,49 \\
\hline Post-intervention costs & & $1.839,64$ & 28,36 & $2.628,13$ & 56,72 \\
\hline Other treatments (Qutenza) & $1200,00 /$ treatment $^{\mathrm{D}}$ & 106,21 & 0 & 106,21 & 0 \\
\hline Radiology & $94,71 / x-$ ray $^{b}$ & 0 & - & 8,61 & - \\
\hline $\begin{array}{l}\text { Complication costs related to } \\
\text { intervention }\end{array}$ & & $1.648,40$ & - & $2.388,00$ & - \\
\hline Lead revision & Various $^{\mathrm{b}}$ & 130,96 & - & 130,96 & - \\
\hline Lead replacement & Various $^{\mathrm{b}}$ & 0 & - & 270,81 & - \\
\hline
\end{tabular}




\begin{tabular}{|c|c|c|c|c|c|}
\hline Replacement IPG & Various $^{\mathrm{b}}$ & 0 & - & 468,79 & - \\
\hline SCS system infection & Various $^{b}$ & 499,17 & - & 499,17 & - \\
\hline Subdural hematoma & Various $^{\mathrm{b}}$ & $1.018,27$ & - & $1.018,27$ & - \\
\hline Follow up visits & & 85,03 & 28,36 & 125,31 & 56,72 \\
\hline $\begin{array}{l}\text { Follow up consult pain clinic } \\
\text { pain specialist }\end{array}$ & $32,39 /$ visit $^{\mathrm{D}}$ & 22,08 & 6,94 & 30,91 & 13,88 \\
\hline $\begin{array}{l}\text { Consult pain clinic pain } \\
\text { nurse }\end{array}$ & $16,20 /$ visit $^{\mathrm{b}}$ & 34,76 & 1,16 & 59,06 & 2,32 \\
\hline $\begin{array}{l}\text { Telephonic consultation } \\
\text { pain specialist }\end{array}$ & $12,89 /$ call $^{b}$ & 12,89 & 52 & 12,89 & 11,04 \\
\hline $\begin{array}{l}\text { Telephonic consultation } \\
\text { pain nurse }\end{array}$ & $6,45 /$ call $^{b}$ & 15,30 & 14,74 & 22,45 & 29,48 \\
\hline Other health care costs & & 976,55 & 915,58 & $2.162,26$ & $1.831,16$ \\
\hline Extramural & Various $^{\mathrm{C}}$ & 448,47 & 59,12 & 942,10 & 118,24 \\
\hline Intramural & Various $^{c}$ & 158,34 & 117,52 & 519,77 & 235,04 \\
\hline Paramedical & Various $^{\mathrm{C}}$ & 110,91 & 327,59 & 236,17 & 655,18 \\
\hline
\end{tabular}




\begin{tabular}{|c|c|c|c|c|c|}
\hline Devices & Various $^{c}$ & 95,89 & 60,77 & 123,73 & 121,54 \\
\hline Medication on prescription & Various $^{c}$ & 162,94 & 350,58 & 340,49 & 701,16 \\
\hline Subtotal health care costs & & $16.759,80$ & $1.223,69$ & $18.742,18$ & $2.173,13$ \\
\hline Paid domestic help & Various & 78,12 & 105,04 & 194,37 & 210,08 \\
\hline Informal care & $13,27 / \mathrm{h}^{\mathrm{c}}$ & 402,93 & 150,79 & $1.337,63$ & 301,58 \\
\hline Productivity loss & Various $^{\mathrm{C}}$ & $1.857,76$ & 92,60 & $1.857,76$ & 185,20 \\
\hline $\begin{array}{l}\text { Loss of daily activities (unpaid } \\
\text { work) }\end{array}$ & $13,27 / h^{c}$ & $1.872,68$ & $1.205,30$ & $4.374,51$ & $2.410,60$ \\
\hline Over-the-counter medication & Various & 3,67 & 16,43 & 32,73 & 32,86 \\
\hline $\begin{array}{l}\text { Subtotal non-health care } \\
\text { costs }\end{array}$ & & $4.215,16$ & $1.570,16$ & $7.797,00$ & $3.140,32$ \\
\hline Total societal costs & & $20.974,96$ & $2.793,85$ & $26.539,20$ & $5.313,45$ \\
\hline
\end{tabular}

SCS, spinal cord stimulation group; BMT, best medical treatment group; AH Academic Hospital; ${ }^{a}$ Expressed in 2012 Euros; ${ }^{b}$ Financial Department of Maastricht University Medical Centre+; ${ }^{c}$ ZiNL: Dutch governmental manual for health care cost analysis; ${ }^{d}$ Informed assumption ZiNL: Dutch governmental manual for health care cost analysis. 
Table 2 Baseline demographics and clinical characteristics of the study population.*

\begin{tabular}{|c|c|c|}
\hline $\begin{array}{l}\text { Baseline } \\
\text { characteristics }\end{array}$ & $\operatorname{SCS}(n=22)$ & BMT $(n=14)$ \\
\hline Age - years & $57.1 \pm 12.4$ & $56.5 \pm 8.0$ \\
\hline $\operatorname{Sex}(m / f)-$ no. $(\%)$ & $15 / 7(68 / 32)$ & $9 / 5(64 / 36)$ \\
\hline$\overline{\mathrm{DM}} \mathrm{I} / \mathrm{II}-$ no. (\%) & $3 / 19(14 / 86)$ & $1 / 13(7 / 93)$ \\
\hline MDNS† & & \\
\hline MDNS 0 (\%) & 13.6 & 21.4 \\
\hline MDNS $1(\%)$ & 18.2 & 21.4 \\
\hline MDNS $2(\%)$ & 40.9 & 35.8 \\
\hline MDNS $3(\%)$ & 27.3 & 21.4 \\
\hline Level of education & & \\
\hline Low (\%) & 63.6 & 57.2 \\
\hline Middle (\%) & 27.3 & 7.1 \\
\hline High (\%) & 9.1 & 35.7 \\
\hline Employment status & & \\
\hline Retired (\%) & 31.8 & 21.4 \\
\hline Employed (\%) & 40.9 & 21.4 \\
\hline Unemployed (\%) & 0 & 7.1 \\
\hline Incapacitated (\%) & 22.7 & 21.4 \\
\hline Domestic work (\%) & 4.6 & 28.6 \\
\hline EQ-5D & & \\
\hline Utility score (pooled & 0.25 & 0.33 \\
\hline
\end{tabular}




\begin{tabular}{|l|r|l|}
\hline mean) & ACCEP & TED MANUSCRIPT \\
\hline
\end{tabular}

* Plus-minus values are means \pm SD. DM: Diabetes Mellitus.

† The Michigan Diabetic Neuropathy Score (MDNS) consists of a standardized neurological examination, including vibration sense, light touch, pin prick, tendon reflexes and muscle strength and standard nerve conduction study of 2 motor nerves (peroneal and median) and 3 sensory nerves (sural, median and ulnar) performed on the non-dominant site. Classes are defined as $0=$ no neuropathy; $1=$ mild neuropathy; $2=$ moderate neuropathy and $3=$ severe neuropathy.

‡ The EuroQol-5 dimension questionnaire (EQ-5D) is a health status measure with respect to mobility, self-care, usual activities, pain or discomfort, and anxiety or depression (no problems, some problems, and extreme problems). A utility score of 1 represents "perfect health", 0 represents "death"; and less than 0 "worse than death".

$P$ values were calculated with the use of chi-square test for categorical variables and the independent-samples Student's t-test for continuous variables. No significant between-group differences were observed for any demographic and clinical characteristics. Values are percentages (numbers) unless stated otherwise. SCS: spinal cord stimulation group; BMT: best medical treatment group; DM: diabetes mellitus; MDNS: Michigan Diabetic Neuropathy Score 
Table 3 Bootstrap analyses of the base-case analysis on subtotal and total health care costs for the SCS- and BMT group with a time horizon of 12 months.

\begin{tabular}{|l|l|l|l|}
\hline Cost category & \multicolumn{2}{l|}{ Mean costs (SD) } & \multicolumn{2}{l|}{ Incremental costs (SCS-BMT) } \\
[95\% confidence interval]
\end{tabular}




\begin{tabular}{|l|l|l|l|}
\hline Total societal costs & $26.539,20$ & $5.313,45$ & $21.225,75$ \\
\hline Bootstrapped & $22.357,97(1.125,05)$ & $4.800,06(452,70)$ & $17.557,92[15.204,06 ; 19.932,69]$ \\
\hline
\end{tabular}


Table 4 Results of the base-case-, secondary and sensitivity analyses for SCS and BMT, regarding costs and effects, and incremental cost-effectiveness ratio's (ICER's) with a time horizon of 12 months.

\begin{tabular}{|c|c|c|c|c|c|c|}
\hline & Group & $\begin{array}{c}\text { Total costs }^{\mathrm{a}} \text { at } 12 \\
\text { months }(€)\end{array}$ & $\begin{array}{c}\text { Effectiveness at } 12 \\
\text { months }(Q A L Y)^{b} \text { or } \\
\text { successfully treated } \\
\text { patients }(\%)^{c}\end{array}$ & $\operatorname{ICER}^{\mathrm{d}}(€)$ & $\begin{array}{c}\text { Quadrant } \\
\text { (NE, NW, SE, } \\
\text { SW) (\%) }\end{array}$ & $\begin{array}{c}\text { Probability cost } \\
\text { effective with a WTP } \\
\text { threshold }=€ 80.000(\%)^{\dagger}\end{array}$ \\
\hline \multicolumn{7}{|l|}{ Base-case analysis } \\
\hline \multirow[t]{2}{*}{ Societal perspective } & SCS & $26.539,18$ & $0.58^{b}$ & $94.159,56$ & $\mathrm{NE}(99.6)$ & $\underline{46}$ \\
\hline & BMT & $5.313,45$ & $0.36^{\mathrm{b}}$ & & & \\
\hline \multirow[t]{2}{*}{ Health care perspective } & SCS & $18.742,18$ & $55^{\mathrm{c}}$ & $34.518,85$ & NE (100) & n.a. \\
\hline & BMT & $2.173,13$ & $7^{\mathrm{c}}$ & & & \\
\hline \multicolumn{7}{|l|}{ Secondary analysis } \\
\hline \multirow[t]{2}{*}{$\begin{array}{l}\text { Baseline correction loss of daily } \\
\underline{\text { activities }}\end{array}$} & SCS & $26.539,18$ & $\underline{0.58^{\mathrm{b}}}$ & $82.778,05$ & $\mathrm{NE}(99.2)$ & $\underline{59}$ \\
\hline & BMT & $8.050,79$ & $0.36^{\mathrm{b}}$ & & & \\
\hline
\end{tabular}




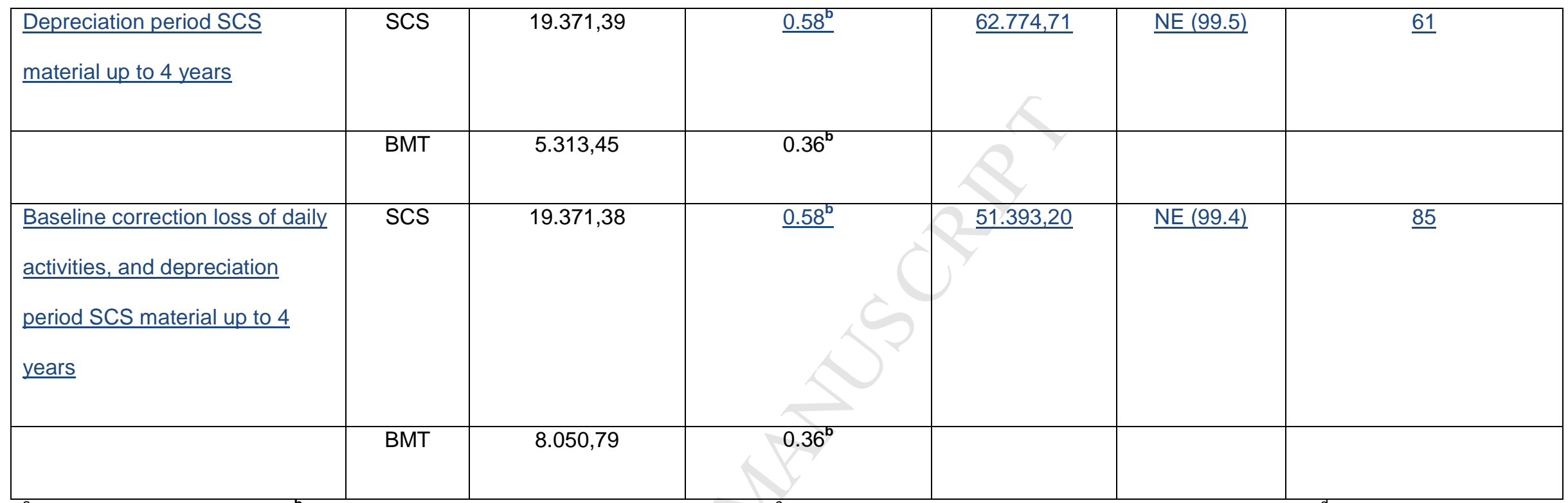

${ }^{a}$ Expressed in 2012 Euro's. ${ }^{b}$ Effectiveness at 12 months expressed in QALY. ${ }^{c}$ Successfully treated patients expressed in percentage. ${ }^{d}$ ICER's: incremental cost-effectiveness ratio's. ${ }^{\text {e }}$ Showing the quadrant were the most points are located expressed in percentage; northwest (NW) quadrant: SCS is more costly and less effective than BMT (inferior); northeast (NE) quadrant: SCS is more costly and more effective than BMT meaning that the cost-effectiveness of SCS depends on the maximum amount of money society is willing to pay for one gain in effectiveness; southeast (SE) quadrant: SCS is less costly and more effective than BMT (dominant); and southwest (SW) quadrant: SCS is less costly and less effective than BMT, meaning that the cost-effectiveness of SCS depends on the minimum amount of money society is willing to accept for loss of effectiveness. ${ }^{\dagger}$ WTP: willingness to pay threshold of $€ 80.000$. 


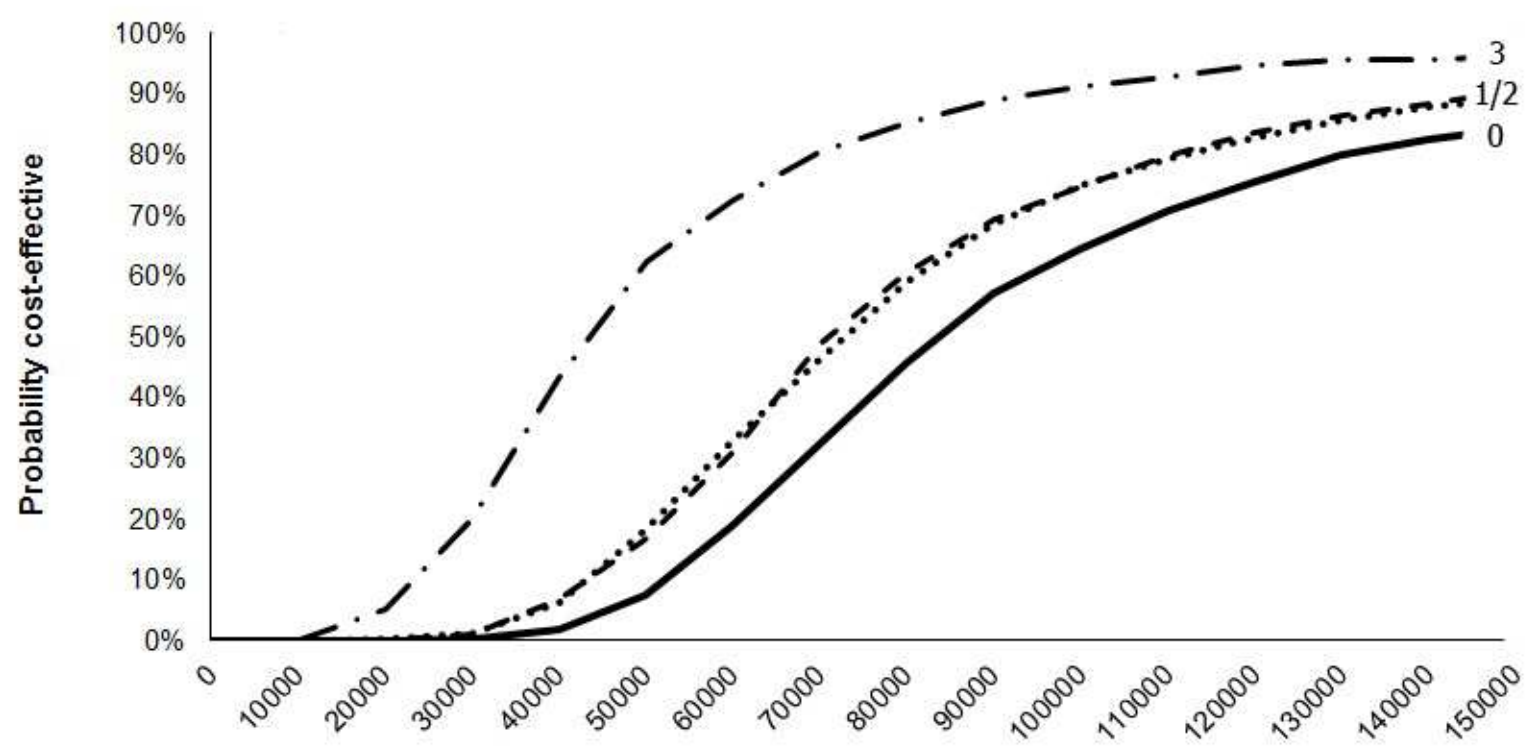

Willingness to pay per QALY 


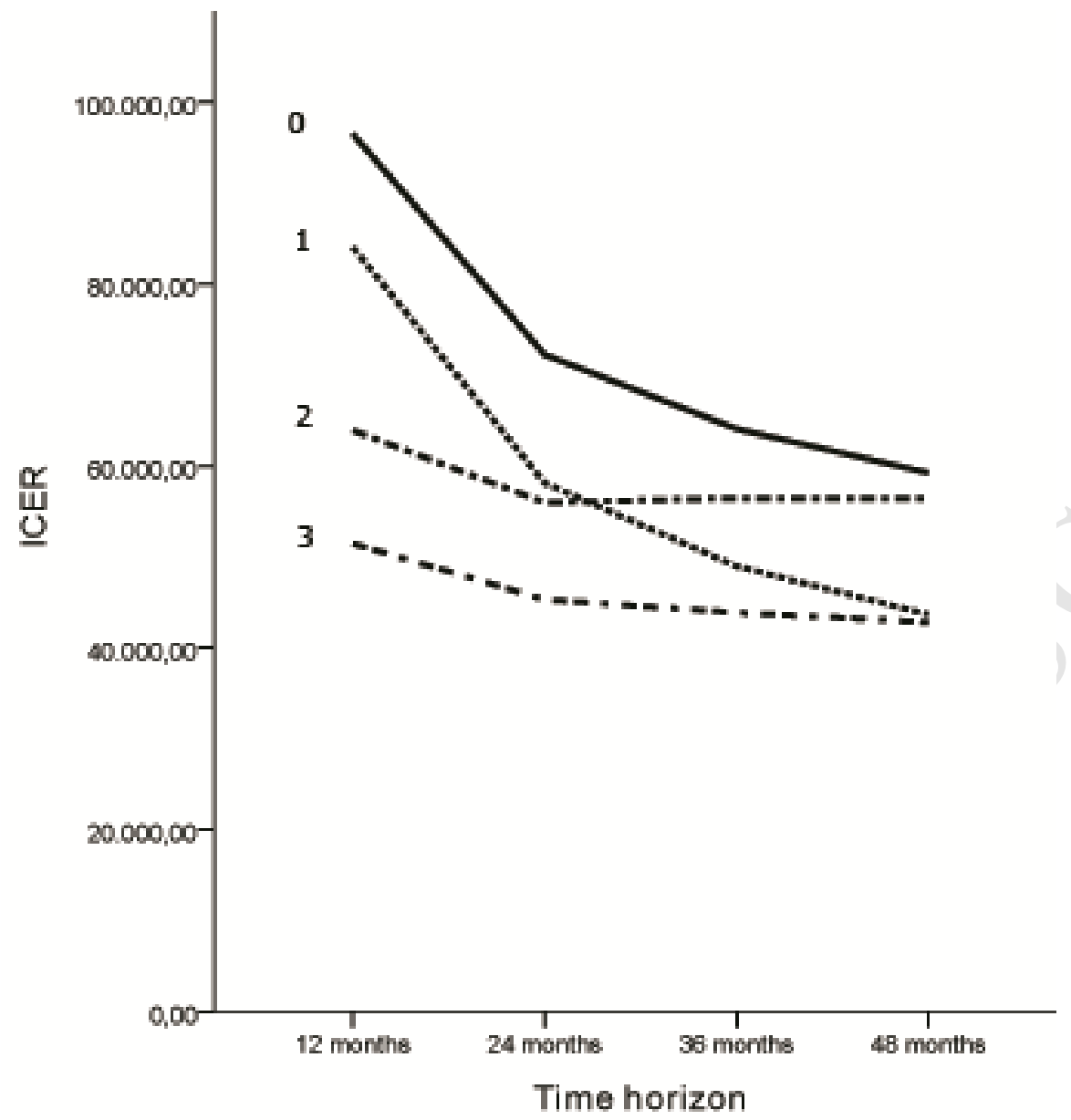


Highlights (core findings of the article and include 3 to 5 bullet points (maximum 85 characters, including spaces, per bullet point)

- Painful diabetic peripheral neuropathy (PDPN) carries a high (economic) burden

- Economic evaluation of spinal cord stimulation (SCS) in PDPN patients

- SCS is not cost-effective at the short term due to substantial initial investment

- Extended follow-up and a model are needed to estimate long term costeffectiveness 